\title{
Bonus Payments within the New Zealand Financial Services Sector
}

\author{
PAUL EASTON* $^{*}$ and DAVID BROUGHAM ${ }^{* *}$
}

\begin{abstract}
Some major corporate scandals have shown that bonuses have been put above basic client needs. As a result, organisations within the financial services sector have been advised to move away from paying bonuses. However, bonus payments are an expected part of the current remuneration package in this sector, which poses an interesting challenge for the employment relationship between employees and organisations. The present study gained employee insights into their bonuses by looking at performance and other factors. Qualitative interviews were undertaken within the financial services sector. Alternatives for bonuses and implications are discussed to manage remuneration and the employer/employee relationship.
\end{abstract}

\section{Introduction and Background}

The financial services sector has come under increasing scrutiny in recent times. Given what has happened internationally, the New Zealand Financial Markets Authority have been focusing on the levels of incentives offered to staff, and the potential behaviours this encourages. They have provided a clear expectation to the industry in New Zealand that salesbased incentives need to be removed (Mitson, 2018). The financial services sector within New Zealand, and internationally, has traditionally operated on a salary plus bonus structure, which has driven behaviours where individuals will focus on activities that deliver sales results leading to the payment of bonuses. Despite international research on incentives and bonuses in this sector (Murphy, 2013), very little is known about how customer-facing employees within this sector view their bonuses and how it interacts with day-to-day operations. This is a very important area to focus on, as initial findings from a recent Royal Commission in Australia, launched in late 2017, pointed to widespread irregularities around some simple banking processes, such as verifying customers' living expenses in loan assessments, charging fees on unauthorised accounts, (sometimes on accounts of deceased customers), and lying to regulators to achieve bonuses. Similar problems have emerged with some high-profile banks within the United States.

The inquiry in Australia resulted in some high-level departures, including the resignation of AMP Insurance CEO (Hutchens, 2018), followed by the Chairman and CEO of National Australia Bank, when the final report was released (Yeates, 2019). With the four main trading banks in New Zealand being owned by Australian parent banks, although separately governed in New Zealand, it did not take long for the call for some type of local inquiry (Eaqub, 2018). The 2017 report, commissioned by the Australian Banking Commission on Retail Banking Remuneration, recommended that "incentives are no longer paid to any retail staff based directly or solely on sales performance" (Sedgwick, 2017, p. 622). The report confirmed that any change needed to consider the impact on customers as well as employees and needs to be driven from a governance and senior leadership perspective (Australian Banking Association,

\footnotetext{
* Executive Master of Business Administration (EMBA) Graduate, Massey Business School, Massy University, Palmerston North, New Zealand. eastonpl@xtra.co.nz

** Senior Lecturer, Massey Business School, Massey University, Palmerston North, New Zealand
} 
2017). Recommendations 5.4 and 5.5of the final Royal Commission report are that banks fully implement the recommendations of the Sedgwick report, and that they review remuneration systems at least annually, including reviewing not only what staff do, but how they do it (Hayne, 2019).

The Financial Markets Authority and the Reserve Bank of New Zealand announced later in 2018 the expectation for all trading banks in New Zealand to remove sales incentives by September 2019; or provide an explanation about the processes in place to minimise poor conduct that can arise from such incentive programmes (Stock, 2018). With increasing scrutiny on the behaviours of businesses in the sector regarding motivating and rewarding staff, and the impact this has on customers, it is worth considering whether an incentive scheme which involves product sales to provide a financial bonus has any impact on staff engagement. New Zealand banks are being held to account by regulators who are seeking a proactive stance around conduct and culture, and subsequently, the structure and resourcing of work (Everett \& Orr, 2018). Using various theoretical perspectives around expectancy, motivation and equity, this research will seek to explore the current employee outlook of bonuses in the New Zealand financial services sector, and its impact on engagement and performance. More importantly, we will explore what these roles will look like if future bonuses are not paid as they have in the past, given that it has been a key motivational factor and a key part of the employment relations landscape within this industry.

\section{Literature Review}

Employees expect and deserve fair compensation for their efforts just as employers can equally expect a fair day's labour. This relationship is well-recognised by either the Principal-Agent Model (Laffont \& Martimort, 2002) or by Equity Theory (Hatfield et al.,2012). Both these theories/models recognise the notion of a fair day's pay for a fair day's work. This paper will use Equity Theory as a reference point, which recognises that, within relationships, people are concerned about both profit and fairness. While the areas of motivation and satisfaction have been well-researched, there is less research with regards to remuneration and, in particular, pay for performance (Ogbonnaya et al., 2017). Existing work appears to fall into two camps; one being the Self-Determination Theory around the motivating effects of intrinsic rewards, and the other - the motivation by way of financial incentives (Thibault Landry et al., 2017). To be able to answer the research question - what affect do bonus payments have on employee engagement the relationship between these needs to be understood, which is a focus of this research.

Early research suggested a separation between the benefits of intrinsic and extrinsic motivators (Gagné \& Deci, 2005). Intrinsic motivation is undertaking a task or role without any external reward, i.e.: the agent finds it interesting or enjoyable, as opposed to extrinsic, and completing something to achieve a specific outcome or reward (Ryan \& Deci, 2000). "According to Equity Theory people perceive a relationship to be fair and equitable when the rewards they reap are commensurate with their contributions to that relationship" (Hatfield et al., 2012, p. 1). Gagné and Forest (2008) add that "fairness is also an important predictor of autonomous work motivation" (p. 229). The final of the foundation theories is Vroom's Expectancy Theory (Kuvaas, 2006). This theory argues that people will act a certain way depending on the expected outcome, which can include bonuses, salary increases and promotions. The theory focuses on three components: expectancy - effort leads to performance; instrumentality - performance leads to outcome, and valence - outcome leads to reward (Robbins \& Judge, 2013). Financial 
incentives can impact valence and motivate individuals to higher-level goals and personal commitment to the organisation (Garbers \& Konradt, 2014). However, as noted, these financial incentives may not be an option for managers and organisations moving forward, thus, other engaging factors need to be explored within this industry.

When exploring the idea of fairness and perceptions of justice in compensation, the two types of justice associated with this area need to be considered - distributive justice and procedural justice. Distributive justice is concerned with the socially just distribution of goods in a society. Developed by Rawls (1971), it follows from his theory of the original position. Procedural justice develops over time and is the idea of fairness in the process that resolves disputes and allocates resources (Tornblom \& Vermunt, 2016). From a compensation perspective, this can help determine whether the level of pay was determined in a fair and just way (Olafsen et al., 2015). Distributive justice is recognised as a strong characteristic of any compensation system (Gagné \& Forest, 2008). People who perceive their payment as inequitable may change their behaviour. This could include working harder to get a better result next time, working less to justify the lesser payment, or even quitting their role altogether (Rynes et al., 2004). A small payment may be worse than no payment at all and damaging to work morale (Chen, 2018).

\section{Bonus Payments}

Employees can make an easy and rational link between additional effort and additional financial reward (Ogbonnaya et al., 2017), as a base level of remuneration may be considered as an indicator to them as to their own competence or value to the organisation (Kuvaas, 2006). Vroom's Expectancy Theory posited that additional financial rewards could be used as a motivator as long as the employee felt confident that the behaviours to achieve the expected results could be produced (Kuvaas, 2006).

The unintended consequences of any reward system also need to be considered, as employees may engage in unethical behaviour to achieve incentivised results (Robbins \& Judge, 2013). Another unintended consequence is how the payment of an incentive to one employee could impact negatively on the motivation of other employees within the same job role (Heywood \& Wei, 2006). An employee's affinity or commitment to the institution for which they work can also lead to unethical practices. However, when this is associated with a bonus payment, the employee feels vindicated in their decision (Danilov et al., 2013). If intrinsic motivation is "crowded out" then the financial reward and extrinsic motivation needs to be sufficient to replace the reduced level of intrinsic motivation, otherwise there is an overall loss of work motivation (Chen, 2018).

To be effective, any bonus scheme needs to consider the complexity of the task. The more complex the task, the less effective a performance bonus is likely to be. Where the reward is contingent on performance, monetary rewards are the most simple and effective, although the overall magnitude of the incentive is also important. If the bonus gets too large as a proportion of overall earnings, risk aversion may occur in order to minimise any financial downside. Where bonus payments are dependent on any group or team activity, better results are evident from smaller homogenous groups. Garbers \& Konradt (2014) found that there was an overall positive correlation between financial incentives and performance; and was more pronounced in field studies rather than laboratory studies. This is interesting and perhaps not unexpected. The question that remains unanswered is whether this also leads to improved engagement with the organisation or provides employees a reason to consider other employment with a better incentive programme. Employees may see an annual bonus payment as recognition for achievements only in the last year (Kuvaas, 2006). 
Pay satisfaction is widely discussed in the literature and can include base pay, bonus or lumpsum payments, other benefits, pay administration and organisational justice perceptions. If these factors are overlooked or not well-managed, this can lead to dissatisfaction, absenteeism, and staff turnover. Furthermore, a distrust in management and potentially the perception that pay for performance measures are inaccurate, and any additional effort is not fairly rewarded (Kim et al., 2008). Goals that are determined by others can also be less motivating and even lead to some resistance (Judge et al., 2005).

Rewards that are contingent on performance and requiring measurement and evaluation can negatively impact motivation and be highly damaging if individuals fail to meet the targets or receive the rewards (Gagné \& Forest, 2008). Use of extrinsic rewards provides controlled motivation but has less quality and longevity than intrinsic or autonomous motivation (Olafsen et al., 2015). Different individuals may pursue the same goal for different reasons (Judge et al., 2005). High achievers and performers favour the idea of pay for performance (Rynes et al., 2004), but to be motivating, bonus payment opportunities need to be at least 5 to 10 per cent of base pay (Kuvaas, 2006).

\section{Recognition and Reward}

Along with base pay and financial incentives, there is a lot of support for the provision of nonfinancial recognition and rewards, which can both enhance intrinsic motivation and provide additional extrinsic motivation. Base pay is an expectation of the employer-employee relationship and, if at an appropriate level, a certain level of intrinsic motivation can also be expected. Factors other than additional pay for performance are considered beneficial to enhance this intrinsic motivation, with a view to developing a mutually beneficial relationship, and a level of engagement from the employee. Employees are likely to build strong emotional ties with their employer if they feel listened to, valued, and believe their development needs are being met. They would also be expected to respond positively to their manager (Olafsen et al., 2015). Employees want to be able to use their skills in a meaningful way for their employers, who will in turn reward them by taking care of them and helping them provide for their families, encourage skill and knowledge development, and provide a work-life balance (Chalofsky \& Krishna, 2009).

If the additional reward becomes too specific to a particular part of a role or provides an overall stronger motivation than the desire to complete the core role well, it can lead to a crowdingout effect of intrinsic motivation that may impact the main incentive for the employee to be there in the first place. If not well-designed, a bonus scheme can have a negative overall impact on job satisfaction and performance, and business outcomes can suffer. Employees have an innate sense of fairness and a general understanding of what they and the role are worth, which aligns with equity theory (fair and equitable rewards for the exchange of labour). Ultimately, employees want to feel valued. The present study is interested in what could motivate financial services staff who may need to give up the option for sales targets and bonuses in the near future. Understanding the importance of the bonuses (something that may not have been questioned before at this level), and what other levers of motivation are valued in the industry need more exploration. Given the changes that this industry may face in the future if the availability of pay for performance is reduced through social change or legislation. 


\section{Method}

The project followed purposeful sampling (Bryman \& Bell, 2015) and used three key conditions: (1) respondents were currently in, or had recently been in, roles within the financial services sector where they were (2) predominantly dealing with customers and (3) had the opportunity to earn a performance-related bonus. Due to the limited number of large mainstream banks in New Zealand, it means that several participants from each bank form part of this study. Respondents were from six different banks with no more than three from any one bank. There were no limits on respondents' gender or tenure, nor any other demographics or industry spread. As it transpired, we had a mix of six males and six females from six different organisations. Age or longevity in roles were also not considered as a criteria for selection, and while questions on tenure were asked, length of service in similar roles to their current role averaged at just over 12 years (tabled below).

\begin{tabular}{|c|c|}
\hline $\begin{array}{ll}\text { Age } & \\
20-30 & 2 \\
31-40 & 5 \\
41-50 & 4 \\
51+ & 1\end{array}$ & $\begin{array}{l}\text { Gender } \\
6 \text { males } \\
6 \text { females }\end{array}$ \\
\hline $\begin{array}{l}\text { Role type } \\
\text { Frontline customer facing } \\
\text { Back office / support }\end{array}$ & $\begin{array}{ll}\text { Time in role } & \\
\text { Range } & 1 \text { month to } 14 \text { years } \\
\text { Average } & 8 \text { years }\end{array}$ \\
\hline $\begin{array}{l}\text { Time in type of role / organisation } \\
\text { Range } \\
\text { Average }\end{array}$ & \\
\hline
\end{tabular}

Three pilot interviews were carried out before official data collection commenced, to ensure the interviewee interpretation of questions. An in-depth interview was conducted with each participant who met the sampling criteria. With 12 participants sampling saturation is likely to occur at this point (Guest et al., 2006). All interviews were conducted face-to-face, generally at the work premises of the respondent. A quiet and secure room was requested to minimise distraction and ensure confidentiality, and this was available in every case. Interviews typically were conducted within a one-hour timeframe. Full transcripts were recorded for analysis. Information regarding research ethics and purpose was provided to each participant, ethics was provided by the co-researchers' university (Low Risk Ethics Notification Number: 4000020228).

This research was completed within the interpretive paradigm where participants were provided with an environment in which they could express their own views through a series of open-ended questions in the form of a semi-structured interview (Scotland, 2012). It is important to remember that, when conducting qualitative research, the experience and opinion of the participants are their own reality (Scotland, 2012). Thematic analysis has the advantage of flexibility, but it also requires rigour to ensure themes or patterns are extracted from the data provided. Both Braun and Clarke (2006) and Attride-Stirling (2001) provide a good guideline and structure, while emphasising the retention of flexibility. These guidelines were followed within the present study. Therefore, to confirm the themes three people associated with the 
research read over the participants' comments. The key themes, findings and discussion from these interviews are outlined below.

\section{Findings and Discussion}

This section presents a summary of the findings. The respondents' insights are then related back to the literature. We focus on market salary insights, the importance of recognition and reward, the desire for bonus payments, the importance of transparency and measurement from management, bonus and performance and a world without a bonus before discussing the implications.

\section{Market Salary Insights}

The knowledge or expectation that the respondents were being paid a fair market salary was the most consistent response when considering bonuses within the financial services sector. The literature review makes reference to how the payment of the base salary relates directly to a feeling of competence by the recipient (Kuvaas, 2006). "I went through a market-matching process where they re-evaluated it based on a new job title and that was awesome for me because it was like, right, 'I'm on a fair wicket',' (Respondent C). This was a consistent theme from all respondents, who often mentioned that any bonus payment also needed to be relative to the market. When payment methods are fair, workers tend to have higher pay satisfaction (Heywood \& Wei, 2006).

To response to the question: "If your employer was to permanently remove the availability of bonus payments, which would they need to replace it with to satisfy you?", most respondents noted it needed to be something of a similar cash value, or flexibility around working hours or conditions, with the possibility of reduced working hours being an option. On further exploration and probing, it became clear that an increase in base salary would be the most satisfactory, if one were to forgo the opportunity of a bonus. Some of the responses were: "Increase in the annual salary" (Respondent F); "Purely on day one, just eliminate money. Make it not an issue, and if people are genuinely unhappy with the market rate at that point in time, then they will leave" (Respondent A); and "Higher salary, increase my wages" (Respondent L). These responses support the idea, as presented by Kuvaas (2006), that people want to be paid what they are worth, which, consequently, confirms the level of competence they have for the role. Again, being "on a fair wicket" and these themes align with equity theory.

\section{Importance of Recognition and Reward}

A lot of key motivators for staff do not require a great deal of cost: just commitment and consistency from leadership. Employees regularly list key motivators as: interest from senior management; challenging work; decision-making authority; and an ability to focus on customers (Rynes et al., 2004). Rewards are less likely to be undermining when they are unexpected, non-controlling, and/or contingent on performance (Olafsen et al., 2015). Again, this aligns with expectancy theory which suggests that people act or work in a certain way to expect results, such as recognition and reward because of their behaviour.

In my experience, I've actually seen that you get better performance out of people by actually saying to them - picking up the phone or walking up and saying to them - 'well done, we really appreciate [sic], in fact, here's some 
morning tea shout, in recognition of what you've done'. A \$20 morning tea shout will give you more bang for your buck out of that staff member than what it would by increasing their pay (Respondent $\mathrm{H}$ ).

\section{The Desire for Bonus Payments}

The consistent theme was that people desire bonus payments and generally how to achieve it: "Absolutely want to receive a bonus, and absolutely want to know at the start of the year what is required to get the bonus" (Respondent $\mathrm{B}$ ). Some respondents had the attitude of just doing the best job they could, and if a bonus were received, it was exactly that:

Then if by default, at the end of year, it was an exceptional year and everyone ticked all the boxes that needed to be ticked as a business, there was some sort of cherry on top at the end of the year then that would be good (Respondent A).

Again, this aligns with expectancy theory. Another commonly shared concern was that the availability of a bonus could lead to unacceptable or bad behaviour with employees seeing it as an entitlement, or an opportunity to achieve what was required to get their overall remuneration to a market level. "It should be seen as a reward at the end, not a motivator to do your job, or not a motivator that drives the behaviours to do your job" (Respondent E).

\section{Concerns with Bonus Payments}

This is one theme where our findings differ from the literature. In response to the question "What do you think are some of the dangers of performance-based bonus payments?", it was best summarised by Respondent E "drives wrong behaviours". Interestingly, most who made this comment noted it as a behaviour seen in others; "We've seen enough round town with some competitors" (Respondent E). Other responses to this question included:

"They drive bad, bad behaviour" (Respondent G)

"The obvious ones around behaviours" (Respondent A)

"it could drive sales and lending and all of [those] things at all costs" (Respondent B).

"For some people it can drive the wrong behaviours" (Respondent $\mathrm{H}$ ).

This, in contrast to the literature, which raised more consistent concerns around the negative impact of performance pay undermining the positive impact teamwork could have by rewarding individuals differently; "it can foster a bit of unhealthy competition amongst peers" (Respondent $\mathrm{C}$ ); or creating an imbalance between intrinsic and extrinsic motivation, with a potential for impact on job satisfaction (Kim et al., 2008). These responses can occur when employees come to view money as their main motivation, leading them to work more in isolation (Thibault Landry et al., 2017), and even when a performance pay approach appears to make sense, it brings about the opposite of the desired result (Campbell et al., 1998).

Respondent A suggested a link between the concerns raised in the literature and those raised most commonly by the respondents:

But if you feel like you're underpaid and you're working hard and the only way you're going to earn your keep is through this incentive reward, whatever it may be, that may enable or create bad decisions, or slightly less thorough jobs. 
Shaw and Gupta (2015), in their meta-analysis of 40 years of financial incentives, stated that individuals will react negatively if variations in financial incentives are seen to be unfair; "So, what I'm talking about there is all of a sudden, you're invested in your own needs and not the needs of the people that you are... the other people in the relationship" (Respondent G). This is especially so if the incentives are seen as inequitable as individuals compare their outcomes with others (Stringer et al., 2011). There is also the concern that employees come to expect their bonus if it is regularly received: "I think people in our organisation probably expect their bonus, so there's a little bit of a feeling that you're entitled to it" (Respondent C). This, then normalises the bonus and further undermines the positive impact of teamwork if incentives were not received in any period, and people were interdependent on others for results (Green \& Heywood, 2008).

\section{Transparency and Measurement from Management}

Overwhelmingly, the respondents preferred to know what was expected of them to be eligible to receive a performance-related bonus, as opposed to simply doing a good job and receiving something as determined by the organisation. They also preferred that this be clearly outlined at the start and expressed concern about the ability of employers to change the scheme during the year. Even the respondents who were ambivalent to the availability of a bonus made comments such as: "I like to know what my clear targets are prior to kicking the year off" (Respondent E). Other's responses such as: "I'd like to know at the start, what the target is and work towards that I suppose" (Respondent J) support the literature and its stance on 'clarity', with any motivation created by the availability of a bonus payment requiring knowledge of the expected reward (Chen, 2018).

There was surprisingly little support for respondents for their immediate supervisor to determine bonus amounts. While the immediate supervisor is often best placed to be more subjective in considering some aspects of performance, the perception of bias may also impact negatively on potential benefits for the employer (Green \& Heywood, 2008); "You've also got the contribution to the culture, your team, individual stuff which I guess your boss assesses" (Respondent $\mathrm{E}$ ). Respondent $\mathrm{C}$ noted that some colleagues more actively promoted their own achievements when it came to the time of the year when bonuses were determined and concluded with: "it does feel a bit like showing off". Individual schemes can also have a lower perception of justice than a collective plan (Kuvaas, 2006). "It's always nice to know, obviously, what the measures and things are" (Respondent G).

\section{Bonus and Performance}

Rewarding performance with an additional pay for performance type bonus can undermine intrinsic motivation and feeling of competence. This is especially the case when it is considered that people generally go to work to do a good job, which the respondents all believed they were doing. "Sometimes if you didn't have a good month and you'd get knocked down 10 places or something, you would open that spreadsheet and it would feel really crap" (Respondent B). "You do want to know what good performance looks like, but not with your bonus in mind" (Respondent $\mathrm{G}$ ). The pressure of performance-related pay may detract from any positive impact on job satisfaction and commitment (Ogbonnaya et al., 2017).

A meta-analysis from Deci et al., (1999) concluded that "performance-contingent rewards can also convey substantial positive competence information in cases where the person does well enough to get a level of reward that signifies excellent performance" (p.659). This is supported by comments from Respondent B: "I would think we need to go less 'here's a bonus for 
everyone' type culture and more 'this is a bonus for top, top performers '”. The most soughtafter employees prefer to be in a system which differentiates individual performance (Rynes et al., 2004). "So, I suppose having that monetary incentive at the end of the year does provide that extra drive to hit the numbers and do well" (Respondent J).

Some respondents also felt many aspects of their role that they cannot control. "There are obviously so many things that are out of our control anyway" (Respondent $\mathrm{H}$ ); "that to not have that expectation hanging over you would be fantastic" (Respondent A). This is supported by the idea that being rewarded for a special performance, rather than for simply completing a task had a greater positive effect (Gagné \& Forest, 2008). At least one of the respondents had taken matters into their own hands: "I'll usually give the script to my boss about why I deserve to be at least towards the top of the pack" (Respondent D).

\section{A World Without a Bonus}

To consider replacing an existing cash bonus opportunity, respondents were of the view that it needed to be for something of equal monetary value, even if that was additional time off. Like many of the influencing factors on the motivational impact of a bonus, the age and stage of the respondents was important, as two different people may pursue the same goal but for different reasons (Judge et al., 2005). Respondent K, when asked about her preference for replacing a bonus, replied: "I'd say putting it into leave. Replacing it with annual leave would definitely mean a lot to me. Especially as I've got children".

Other responses to the question: "If you could forgo a bonus what would you replace it with?" included: "I would always forgo a bonus for a higher annual salary just because I like having that certainty of income" (Respondent B); "increase in the annual salary" (Respondent F); and "I think the biggest thing which I'd be more than happy to do is forgo a bonus for a higher base salary" (Respondent $\mathrm{J}$ ). This would indicate, according to the meta-analysis by Cerasoli et al. (2014), a positive impact on engagement as it provides a greater feeling of competence (Kuvaas, 2006), and a higher level of intrinsic motivation. For some people it is the opportunity to try "and whack some off the mortgage, some for a little bit of spending money and then normally some goes on maintenance-type stuff" (Respondent B); while others are happy to be "able to buy new work shoes and get my hair done" (Respondent L). It must be noted that an equitable outcome must still be offered by the employer if the bonus is removed in line with equity theory.

\section{Implications}

Our research shows that there is a strong desire for employees to be paid, firstly, a fair market salary (in line with expectancy theory); that they be provided with the appropriate tools and resources; learning and development opportunities; and the opportunity to be heard, not only by direct supervisors, but also by senior leadership. These themes are also consistent with the literature. Flexibility was another key theme raised, although interestingly this had different meanings to respondents, which depended, to a degree, on 'age and stage', including parents with young children, proximity to home or availability of support. The respondents accept that employment environments cannot always be consistent, but every care should be taken to ensure consistency, where possible. If a bonus scheme or pay for performance option is available, it requires either clear targets and measures (and for these to be delivered upon if they are met), or a more general scheme where there are no measures, but everyone participates. 
The interviews reinforced that intrinsic motivation is what will attract people to a role, along with the ability to contribute to an organisation or a community. The extrinsic motivation of something like a performance incentive may encourage some additional effort. A direct cash payment was generally seen as the best incentive to achieve this. The value added to the business, or potentially detrimental impact of getting an incentive programme wrong, requires more attention. It was interesting that the one area where the literature and interviews disagreed was on the negative impacts of a bonus scheme. Respondents were concerned about the bad employee behaviours driven by a bonus scheme; whereas the literature was more concerned with a poorly designed scheme undermining teamwork or creating a crowding-out effect of the intrinsic motivation that attracted people to the core role.

\section{Limitations}

Limited demographic data was obtained as it was not deemed relevant given the sample size. The key discussions during the interviews centred around about what motivated employees to want to perform well for a current employer, and what, if any part, bonus payments played in that motivation. Their personal experiences with bonuses were discussed, along with the part bonuses might play when considering roles for other organisations. The semi-structured nature of the interviews was advantageous as it became evident that everyone's story was a little different. While this was to be expected, it was also evident this changed what motivated them, and how they viewed bonus payments. Future studies could look to build a larger sample size of interviewees or use a survey-based approach.

\section{Conclusion}

It was evident from the interviews that a bonus scheme or system does create distraction, either from core tasks to achieve a specific result which are independently rewarded, or from workflow in general. This can occur both when results are published and when payments are due to be paid. In a sector where bonus payments are an expected part of the current remuneration package, to remove them would mean a need to be replaced with a similar cash equivalent, most likely an increase in base pay, which holds true with equity theory. Communication between all levels of an organisation needs to be clear and concise and provide all employees with a sense of inclusion and worth. This study provides useful insights into how performance could be achieved where bonuses are no longer used, which will be a key part of employment relations within this industry moving forward.

\section{References}

Attride-Stirling, J. (2001). Thematic networks: an analytic tool for qualitative research. Qualitative Research, 1(3), 385-405

Australian Banking Association. (2017). Banks to change the way they pay their staff. https://www.ausbanking.org.au/banks-to-change-the-way-they-pay-their-staff/

Braun, V., \& Clarke, V. (2006). Using thematic analysis in psychology. Qualitative Research in Psychology, 3(2), 77-101.

Bryman, A., \& Bell, E. (2015). Business Research Methods (4 ${ }^{\text {th }}$ ed.). Oxford University Press. 
Campbell, D. J., Campbell, K. M., \& Chia, H.-B. (1998). Merit Pay, Performance Appraisal, and Individual Motivation: An Analysis and Alternative. Human Resource Management Journal, 37(2), 131-146.

Cerasoli, C. P., Nicklin, J. M., \& Ford, M. T. (2014). Intrinsic Motivation and Extrinsic Incentives Jointly Predict Performance: A 40-Year Meta-Analysis. Psychological bulletin, 140(4), 980-1008.

Chalofsky, N., \& Krishna, V. (2009). Meaningfulness, Commitment, and Engagement: The Intersection of a Deeper Level of Intrinsic Motivation. Advances in Developing Human Resources, 11(2), 189-203.

Chen, C-A. (2018). “A Little Is Better Than Zero" or "Pay Enough or Don't Pay at All”? Evidence on the Size of Pay-for-Performance Across the Sectors. Public Personnel Management, 47(2), 119-143.

Danilov, A., Biemann, T., Kring, T., \& Sliwka, D. (2013). The dark side of team incentives: Experimental evidence on advice quality from financial service professionals. Journal of Economic Behavior \& Organization, 93, 266-272.

Deci, E. L., Koestner, R., \& Ryan, R. M. (1999). A meta-analytic review of experiments examining the effects of extrinsic rewards on intrinsic motivation. Psychological bulletin, 125(6), 627-668.

Eaqub, S. (2018, February 18). Australian banking review is overdue in NZ too. Stuff. https://www.stuff.co.nz/business/opinion-analysis/101455958/australian-bankingreview-is-overdue-in-nz-too

Everett, R., \& Orr, A. (2018). Letter sent to banks by the FMA/Reserve Bank of New Zealand [Press release]. Financial Markets Authority. https://fma.govt.nz/news-andresources/media-releases/letter-sent-by-the-fma-reserve-bank-of-new-zealand/

Gagné, M., \& Deci, E. L. (2005). Self-Determination Theory and Work Motivation. Journal of Organizational Behavior, 26(4), 331-362.

Gagné, M., \& Forest, J. (2008). The Study of Compensation Systems Through the Lens of SelfDetermination Theory: Reconciling 35 Years of Debate. Canadian Psychology/Psychologie canadienne, 49(3), 225-232.

Garbers, Y., \& Konradt, U. (2014). The effect of financial incentives on performance: A quantitative review of individual and team-based financial incentives. Journal of occupational and organizational psychology, 87(1), 102-137.

Green, C., \& Heywood, J. S. (2008). Does Performance Pay Increase Job Satisfaction? Economica, 75(300), 710-728.

Guest, G., Bunce, A., \& Johnson, L. (2006). How many interviews are enough? An experiment with data saturation and variability. Field Methods, 18(1), 59-82. 
Hatfield, E., Rapson, R. L., \& Bensman, L. (2012). Equity Theory. In V. S. Ramachandran (Ed.), Encyclopedia of Human Behavior (2 ${ }^{\text {nd }}$ ed.) (pp. 73-78). Academic Press.

Hayne, K. M. (2019). Royal Commission into Misconduct in the Banking, Superannuation and Financial Services Industry (Volume 1). Commonwealth of Australia. https://www.royalcommission.gov.au/sites/default/files/2019-02/fsrc-volume-1final-report.pdf

Heywood, J. S., \& Wei, X. (2006). Performance Pay and Job Satisfaction. Journal of Industrial Relations, 48(4), 523-540.

Hutchens, G. (2018, April 20). Banking royal commission: all you need to know - so far. The Guardian. https://www.theguardian.com/australia-news/2018/apr/20/banking-royalcommission-all-you-need-to-know-so-far

Judge, T. A., Bono, J. E., Erez, A., \& Locke, E. A. (2005). Core self-evaluations and job and life satisfaction: The role of self-concordance and goal attainment. Journal of Applied Psychology, 90(2), 257-268.

Kim, S., Mone, M., \& Kim, S. (2008). Relationships Among Self-Efficacy, Pay-forPerformance Perceptions, and Pay Satisfaction: A Korean Examination. Human Performance, 21(2), 158-179.

Kuvaas, B. (2006). Work performance, affective commitment, and work motivation: the roles of pay administration and pay level. Journal of Organizational Behavior, 27(3), 365385.

Laffont, J.-J., \& Martimort, D. (2002). The Theory of Incentives: The Principal-Agent Model. Princeton University Press.

Mitson, E. (2018). Incentives for bank staff too highly focused on sales [Press release]. Financial Markets Authority (FMA). https://www.fma.govt.nz/news-andresources/media-releases/incentives-for-bank-staff-too-highly-focused-on-sales/

Murphy, K. J. (2013). Regulating banking bonuses in the European Union: a case study in unintended consequences. European Financial Management, 19(4), 631-657.

Ogbonnaya, C., Daniels, K., \& Nielsen, K. (2017). Does contingent pay encourage positive employee attitudes and intensify work? Human Resource Management Journal, 27(1), 94-112.

Olafsen, A. H., Halvari, H., Forest, J., \& Deci, E. L. (2015). Show them the money? The role of pay, managerial need support, and justice in a self-determination theory model of intrinsic work motivation. Scandinavian Journal of Psychology, 56(4), 447-457.

Rawls, J. (1971). A Theory of Justice. Harvard University Press.

Robbins, S. P., \& Judge, T. (2013). Organizational Behaviour (15 ${ }^{\text {th }}$ ed.). Pearson/Prentice Hall.

Ryan, R. M., \& Deci, E. L. (2000). Intrinsic and Extrinsic Motivations: Classic Definitions and New Directions. Contemporary Educational Psychology, 25(1), 54-67. 
Rynes, S. L., Gerhart, B., \& Minette, K. A. (2004). The importance of pay in employee motivation: discrepancies between what people say and what they do. Human Resource Management, 43(4), 381-394.

Scotland, J. (2012). Exploring the Philosophical Underpinnings of Research: Relating Ontology and Epistemology to the Methodology and Methods of the Scientific, Interpretive, and Critical Research Paradigms. English Language Teaching, 5(9). http://dx.doi.org/10.5539/elt.v5n9p9

Sedgwick, S. (2017). Retail Banking Remuneration Review. https://www.retailbankingremreview.com.au/wpcontent/uploads/2017/04/FINAL_Rem-Review-Report.pdf

Shaw, J. D., \& Gupta, N. (2015). Let the evidence speak again! Financial incentives are more effective than we thought. Human Resource Management Journal, 25(3), 281-293.

Stock, R. (2018, November 6). Banks given deadline to end high-pressure sales incentives. Stuff. https://www.stuff.co.nz/business/money/108356295/banks-given-deadline-toend-highpressure-sales-incentives? $\mathrm{rm}=\mathrm{m}$

Stringer, C., Didham, J., \& Theivananthampillai, P. (2011). Motivation, pay satisfaction, and job satisfaction of front-line employees. Qualitative Research in Accounting \& Management, 8(2), 161-179.

Thibault Landry, A., Gagné, M., Forest, J., Guerrero, S., Séguin, M., \& Papachristopoulos, K. (2017). The relation between financial incentives, motivation, and performance: An integrative SDT-based investigation. Journal of Personnel Psychology, 16(2), 61-76.

Tornblom, K. Y., \& Vermunt, R. (2016). Distributive and procedural justice: research and social applications. Routledge.

Yeates, C. (2019, February 7). 'Deeply Sorry' NAB Chair and CEO both resign after horror week. The Sydney Morning Herald. https://www.smh.com.au/business/banking-andfinance/nab-ceo-and-chairman-resign-20190207p50wbx.html\#: :text=After\%20a\%20horror\%20week\%20for,at\%20the $\% 20$ end $\% 20$ of\%20February. 